\title{
ТАТЬЯНА БлИНКовА
}

Московский городской педагогический университет (Москва, Россия)

\section{Функционирование лексического блендинга в разных стилях немецкого языка}

Настоящее исследование посвящено функционированию лексического блендинга в разных стилях немецкого языка. Блендинг (контаминация) - способ словообразования, заключающийся в соединении двух усеченных или одной усеченной и одной полной основ в одну лексическую единицу.

Как отмечает Н. А. Лаврова, образование блендов находится на стыке лингвистической компетенции и креативности, и поэтому блендинг является частью лингвистической компетенции носителей языка. Автор также подчеркивает, что основное функциональное назначение блендов - игровое словотворчество, вызванное стремлением личности к самореализации, креативности, стремлением избежать клишированности речи и другими причинами. При этом творческое отношение индивидуума к слову предполагает оригинальность, экспрессивность, оценочность, эмоциональность, гибкость, способность и желание создавать слова, расширяющие морфологический и семантический потенциал языковых знаков (Лаврова 2013: 3).

Широкая распространенность блендов связана с тем, что блендинг как словообразовательная модель является наиболее эффективным способом компрессии информации в рамках одной лексемы. Активизация блендов в настоящее время обусловлена сдвигом интереса от сущности предмета или явления к отношению субъекта к предмету или явлению, вследствие чего возникают эмоционально-экспрессивные и оценочные синонимы узуальных лексем (Лаврова 2013: 10). Распространению блендов в большой степени способствует английский язык, так как именно на его почве на протяжении $\mathrm{XX}$ века создавались многочисленные бленды. Кроме того, типология английского языка, в частности, одноморфемная структура слова и отсутствие флексий, способствует образованию блендов на его почве (Лаврова 2013: 3). Важно отметить, что, в отличие от английского языка, в немецком языке начали заниматься блендами только в 90-е годы XX века.

Основную теоретическую базу настоящего исследования составляют две диссертации, посвященные блендингу в немецком языке. 
О. А. Надькина в своей работе рассматривает блендинг как явление психологическое, языково-мыслительное, бленды как фиксацию одного из звеньев речемыслительного процесса. Новым в работе является то, что контаминация изучается с точки зрения личностной мотивации, личностного смысла. Автор выдвигает гипотезу о том, что блендинг необходимо рассматривать в рамках общей психофизиологической теории эмоций, согласно которой эмоционально нейтральных состояний в жизнедеятельности человеческого организма быть не может. Следовательно, контаминация может служить показателем эмоционально окрашенной речи. Автор отмечает, что спонтанные скрещенные единицы - результат эмоциональной регуляции неосознанного плана, которая характерна для ситуаций неподготовленной речи. Автор также утверждает, что в блендах оказываются скрещенными не значения лексических единиц, а личностные смыслы, которые возникли при субъективном познании окружающей индивида действительности (Надькина 1991: 12). Что касается поэтической речи, автор акцентирует внимание на том, что намеренная контаминация не является ошибкой, это результат сознательной работы писателя или поэта. Намеренная контаминация может выполнять разные стилистические функции, например, указывать на необразованность персонажа или характеризовать персонажа-иностранца. В частности, намеренные контаминации могут являться результатом лингвистических опытов, направленных на игру словом (Надькина 1991: 13).

Работа К. Фридрих посвящена структуре и функционированию блендов в немецком языке. Автор подчеркивает, что блендинг является очень продуктивным способом словообразования в немецком языке. К. Фридрих делит найденные бленды на следующие тематические группы: продукты питания (Hellikatesse (hell+Delikatesse) - плакат фирмы Paulaner, рекламирующий светлое пиво, которое они считают деликатесом); досуг и туризм (Urlaubär (Urlaub+bär) - водная игрушка в форе медведя, которую часто берут в отпуск); культура и искусство (Liebesmü'sique (Liebesmühe+musique) - название программы одного вокального ансамбля, который в своих песнях поет о любовных муках); спорт (Beckingham Palast-Beckham + Buckingham Palace - название дома Бекхема и его супруги, напоминающего Букингемский двореи); политика (Lasst euch nicht edmundigen! (Edmund Stoiber+entmündigen (брать под опеку) - баварский плакат 2003 год против премьер-министра Эдмунда Штойбера); наука (Schiege (Schaf + Ziege) - гибрид овиьы и козы); общество (Ökolozismus (Ökologie + Katholizismus) - образование, сочетающее в себе экологию и католицизм); техника (BrakeMatic (brake + automatic) - тормозное автоматическое устройство) и др. (Friedrich 2008: 173).

Автор выяснила, что бленды в немецком языке встречаются во всех стилях. В научном стиле уже XIX века бленды стали распространяться в научном стиле, так как появилась необходимость в создании новых терминов (например, Bionomie - биономия, Morphonologie - морфонология), при этом 
многие термины из техники и экономики заимствовались из английского языка.

Что касается масс-медиального дискурса, автор выявила наличие блендов в разных газетах и журналах: политических, молодежных, женских, о бизнесе, автомобилях, путешествиях. Некоторые журналы, позиционирующие себя как инновационные, включают бленды в свои названия (AirLEBNISBLATT (Airport+Erlebnisblatt) - реклама дискотеки Аэропорт, освещчающей все, что там происходит, как яркие события; Vorsicht StuVe! (Vorsicht Stufe + StuVe! (студенческое собрание) - название газеты, выпущенной студенческим собранием с намеком на то, что его нельзя недооценивать). Бленды часто включаются в заголовки на обложках журналов и подписи к картинкам: AbentEuro (Abenteuer+Euro) - заголовок статьи, автор которой испытывает противоречивые чувства к введению евро, NACHTDENKEN (Nacht + nachdenken - ночное размыиление) - подпись под фотографией профессора Дж. Серля в университетской библиотеке, где он размышилят по ночам в одиночестве) - с целью привлечь внимание читателей, пробудить их любопытство и заставить их купить газеты и журналы (Friedrich 2008: 200).

Автор подчеркивает также широкое распространение блендов в рекламе, что связано с тем, что фирмы и производители продуктов хотят, чтобы их продукты выглядели в глазах клиентов оригинальными и привлекательными. Такие бленды вызывают ассоциации, связанные с эстетикой, креативностью и инновационной силой и оказывают сильное эмоциональное воздействие на читателей. Автор обнаружила, что бленды в рекламе часто содержат позитивную коннотацию и вызывают приятные ассоциации (pfanntastisch (сковорода + фантастический) - реклама отличных сковородок), internet (характеристика качественной и привлекательной для клиентов программы в Интернете), негативно окрашенные бленды встречаются редко (Sixt kämpft gegern den Massenteurismus - Сикст (фирма, занимающуаяся продажей и арендой автомобилей) борется с массовым подорожанием). Автор отмечает, что бленды в рекламе часто выполняют апеллятивную и фатическую функции: VERABSCHWEDET EUCH (Verabredet euch + Schweden-oбъявление об открытии ИКЕИ в одной из земель Германии, где немцев приглашают прийти за покупками именно в иведский магазин), Kaиfwiedersehen! - до свидания! Спасибо за покупку! (Friedrich 2008: 206).

К. Фридрих выяснила, что в разговорной речи бленды, кроме номинативной функции, часто несут интегрирующую или изолирующую функции. Они используются для того, чтобы отгородить себя от остального общества и обозначить принадлежность к какой-то группе. Сферы их употребления включают сценическую речь (Sillywood - глуnылй Голливуд, Voice Jail System - система голосовых сообщений с таким количеством опичй, что легко становишься ее заложником), речь молодежи (Schlunze (Schlampe 
+ Plunze) - небрежно одетая молодая женщина, Krokofantös (Krokodil + elefantös) - замечательно), и студентов (UniVersum (университетский мир (Uni+universum) (лam), Guten Morgend! (Guten Morgen + Guten Abend) - npuветствие людей, которые встают слишком поздно), язык пользователей Интернета (Chatiquette - этикет для общения в чатаx, sich mailden - подписаться на рассылку/новости через электронную почту). Автор отмечает, что подобные бленды в эстетической функции встречаются и в речи взрослых, желающих лучше узнать возможности словообразования, показать свое сознательное отношение к языку и с целью языковой игры (например, Lexikonster (Lexicon + Monster - название игры на уроке родного языка для школьников, где они должны образовывать бленды и объяснять их), Stalinopoly (Сталинополис). Такие бленды часто встречаются в шутливых прозвищах членов семьи, друзей или коллег по работе (Starkus (cuльный Mapкус), Cornsula (шуточное имя для сестер Корнелия и Урсула, которых родители часто путают). Автор отмечает, что создатели таких блендов часто стремятся казаться смелыми, модными и современными (Friedrich 2008: 217).

На данном этапе нашего исследования были найдены и расклассифицированы примеры из корпуса DwDS из масс-медиального дискурса, стиля художественной литературы и научного стиля.

По происхождению бленды были разделены на английские заимствования - самая большая группа - Carjacking (car+hijacking - захват автомобилей) Netiquette (Internet+etiquette - правила поведения в Интернете), собственно немецкие бленды Demokratur (Demokratie + Diktatur - форма правления, представляющая собой смесь демократии и диктатуры), Schwenglisch (Schwabien + English - швабский английский) и гибриды Glamping (glamourös + Camping - кемпинг в гламурных палатках, Straußencopter (Straußen + Helicopter - вертолет в форме страуса).

С точки зрения тематики были выделены бленды, связанные с естественными науками и техникой - Anthrozoologe (Anthropos + Zoologe - cneииалист, совмещающий в себе антрополога и зоолога), Cybernaut (cyber + astronaut - активный пользователь Интернета); искусством и развлечениями - Provokunst (Provocation + Kunst - провокачионное искусство), Jazzolektrik (Jazz + Elektrik - стиль в музыке, совмещающий черты джаза и электроники); политикой (Westalgie (Westen + Nostalgie) - ностальгия жителей западных земель по ГДР), Jurokratie (Jurist + Bürokratie - бюрократия, основанная на власти юристов); лингвистикой - Denglisch (Deutsch + Englisch) - немеикий с примесью английского, Sprechanismus (sprechen + Mechanismus) - механизм речи; людьми - Indiskretin (indiskret + Kretin -беcтактный кретин), Snoblesse (Snob + Noblesse - благородный сноб).

Также бленды были поделены на группы с точки зрения стилистической окраски: 1) стилистически нейтральные термины, например, Politesse (Polizei + Hostess) (женщины-полицейские): 
Politessen in Paris haben nun eine neue Aufgabe. Sie müssen keine Strafzettel mehr für den privaten Parkplatz schreiben, doch Falschparker unerbittlich bestrafen. - У женцин-полицейских в Париже теперь новое задание. Они должны не выписывать штрафы на частных парковках, а беспощадно штрафовать тех, кто неправильно паркуется (Wikipedia). Здесь бленд обозначает новый термин в тематической группе «профессии», так как полицейскими традиционно являются мужчины;

2) стилистически окрашенные слова;

a) экспрессивы, например, Besserwessi (Besserwisser + Wessi):

«Wir sind ein dummes Volk!»-Ironische Repliknicht nur aufdie Deklaratione, die aus den Regierungsämtern herüberschallten, sondern auch auf die OberlehrerAttitüden der Besserwessis. Inzwischen haben sich die Erfahrungen mit den Verdummungspraktiken akkumuliert, mehr aber noch mit den Konsequenzen, die daraus resultieren. - «Mы глупый народ!» - это ироническая реплика не только о декларациях, которые провозглашаются государственными учреждениями, но также и об отнотении надменных жителей старых земель, которые любят поучать. Между тем подобный опыт был аккумулирован в практиках одурачивания, правда, это больше имело последствия, которые явились результатом этого (Die Zeit, 17.05.1991, Nr. 21). Экспрессия в данном контексте складывается из отрицательного коннотативного компонента слова Besserwisser - всезнайка (неодобрительно), выражает негативное отношение людей из новых земель к западным немцам), присутствует здесь также и эстетическая функция;

б) оценочные слова, например, Ehrgeizhals (Ehrgeiz + Geizhals):

Ich nahm diese Zahlen und ging damit eine Treppe höher, wo ein Professor der Mathematik wohnt, und bat ihn, mir das mal schnell zu subtrahieren. Der Mann war ein Ehrgeizhals, er fing gleich an zu rechnen und schrieb eine Menge Zahlen zusammen. - Я взял эти числа и поднялся с ними на одну ступеньку, где живет профессор математики, и попросил его быстро вычесть их для меня. Этот человек был чрезмерно честолюбив, он смог одновременно посчитать и написать кучу чисел вместе (Lehmann, Arthur-Heinz, Mensch, sei positiv dagegen!, Dresden: Heyne 1939, S. 39). В данном контексте подчеркивается ироническое отношение автора к честолюбию.

Также бленды были разделены на группы в зависимости от преобладающей функции. Были выявлены следующие наиболее ярко выраженные функции: - 1) номинативная, например, Tomoffel (Tomaten + Kartoffel):

Durch Verschmelzung zweier Einzelzellen schuf der Tübinger Pflahzengenetiker Professor Georg Melchers zusammen mit zwei Kollegen 1978 bizarre Mischpflanzen aus Kartoffel und Tomate. Melchers Pflanzenbastarde; Tomoffeln und Kamaten, blieben freilich unfruchtbar. - Путем скрещивания двух отдельных клеток профессор Георг Мелхерс, генетик из Тюбингена, занимающийся растениями, вывел с двумя своими коллегами 1978 причуд- 
ливых гибридов растений, полученных из томата и картофеля. Однако Гибриды Мелхерса, томоффель и камат, оказались неспособными к размножению (Die Zeit, 25.09.1981, Nr. 40). В данном контексте бленд - термин из биологии обозначает новый вид растения, выведенный недавно, бленды такого типа фиксируют прогресс в науке;

2) эстетическая, например, Snoblesse (Noblesse + Snob):

Unsere Modenberichterstatterin, Frau Kasimira von Flechthaar, hatte Snoblesse oblige - Gelegenheit, dem Brückeneinsturz beizuwohnen. - Hau cneичалист по моде, которая докладывала о положении дел, Фрау Казимира фон Флехтхаар, имела - как все благородные снобы-возможность присутствовать при разрушении стены (Tucholsky, Kurt, Der Pont de l'Alma fliegt in die Luft!, in: Kurt Tucholsky, Werke - Briefe-Materialien, Berlin: Directmedia Publ. 2000). Эстетическая функция основана на сочетании слова благородный, обозначающего положительное моральное качество человека, и слова сноб, имеющего отрицательную коннотацию. В данном контексте речь идет о человеке, который с одной стороны, является заносчивым снобом, а с другой - благородным по своему происхождению и поведению. Подчеркивается, что не все, а только определенные слои населения, имели возможность присутствовать при таком ключевом событии, как разрушение стены;

3) лудическая, например, Deinung (Dein + Meinung):

Es geht in Anlehnung an das Kinderbuch «Pu der Bär» um ein Buch von Harry Rowohlt mit dem Titel «Pooh's Corner» - für alle, die eigene kleine Kinder haben, sofort identifizierbar, der Bär ist entsprechend erkennbar - mit dem Untertitel «Meinungen und Deinungen eines Bären von geringem Verstand». Здесь наблюдается ориентация на детскую книжку «Винни-Пух», на книгу Гарри Ровольта «Уголок Винни-Пуха», для всех, у кого есть маленькие дети, его можно идентифицировать, медведь соответственно узнаваем, подзаголовок «мои мнения и мнения медведя об этой незначительной теме» (Die Zeit, 21.06.1996, Nr. 26). Игра слов основана на сходстве в звучании и значении притяжательных местомений Mein и Dein. Слово Meinung изначально основано от Mein, но позже этот смысл оказался утерян, игра слов явно указывает на этимологию слов, слегка с ироническим оттенком;

4) оценочная, например, Elefantastisch (elefant + fantastisch):

Mit diesem Buch erscheint das seit Zetteps Traum wohl elefantastischste Geschöpf auf dem deutschen Buchmarkt, ein Monument deutscher Wertarbeit, der Spinnerei und des poetischen Magnetismus. - $C$ этой книжкой на немеиком книжном рынке появляется совершенно потрясающее творение, памятник высококачественной немеикой работе, тонкой работе и поэтическому очарованию (Die Zeit, 21.02.1992, Nr. 9);

5) экспрессивная, например, Affenteuerlich (Affe + Abenteuerlich):

Aber es ist doch lustig zu sehen, wie sich dieser Industriellentypus in den Augen eines Franzosen darstell, der die Deutschen nicht haßt (man haßt überhaupt 
keine Völker - sie sind einem unangenehm ), wie sich der bewegt, mit dem Hakenkreuz im Manschettenknopf. Die Geschichte ist ein wenig affenteuerlich, aber hübsch bunt. - Но очень забавно наблюдать, как этот индустриальный тип смотрится в глазах франиуза, который не испытывает ненависть к немцам (нет народов, которых он ненавидит - они ему неприятны), как он себя ведет, со свастикой, вмонтированной в запонку на манжете. История не то чтобы уюсасно захватывающая, но очень яркая (Tucholsky, Kurt, Der neue Morand, in: ders., Kurt Tucholsky, Werke - Briefe - Materialien, Berlin: Directmedia Publ. 2000). В данной ситуации экспрессивная функция бленда основана на экспрессивной коннотации слова Affen (в переносном значении: наречие-интенсификатор, означающее «ужасно, до чертиков»).

Многие слова сочетают две и более функций, например, в слове Verschlimmbessern сочетаются оценочная, эстетическая и лудическая функции:

Schlimmer ist die mangelnde Überzeugung von der Güte des Buches. Ich feile, verbessere, mache Zusätze, u. wahrscheinlich verschlimmbessere ich oft. Mit welcher blinden Selbstverständlichkeit habe ich die Moderne Prosa in relativ kurzer Zeit geschrieben! - Недостаточная уверенность в себе негативно отражается на качестве книги. Я совершенствую ее, улучиаю, дополняю и возможно таки образом и улучшаю, и ухудшаю ее качество. И как, я, сам того не замечая, написал современную прозу за относительно короткое время! (Klemperer, Victor, [Tagebuch] 1928, in: ders., Leben sammeln, nicht fragen wozu und warum, Berlin: Aufbau-Taschenbuch-Verl. 2000). Игра слов в данной ситуации заключается в соединении антонимов verschlimmen и verbessern, здесь имеет место оксюморон-сочетание несочетаемых слов, присутствует положительная и одновременно отрицательная оценка. Слово verschlimmbessern в данном контексте подчеркивает противоречивое отношение и амбивалентные чувства автора по поводу своего творчества.

В бленде Schmutzengel имеют место лудическая, эстетическая и оценочная функции:

Noch aus einem anderen Grund sind die Männer vom Müll neidisch auf die Handreiniger-Kollegen. Die dürfen nämlich bei der Love Parade sauber machen und bekommen als Bonus ein T-Shirt mit jährlich wechselndem Motiv (beispielsweise «Schmutzengel») - Ecmь еще одна причина, по которой мусорщики могут завидовать своим коллегам, занимающимся уборкой своими руками. А именно, они могут наводить чистоту во время парада любви и получают как бонус футболку с надписью, которая каждый год меняется (например, «ангел грязи») (Die Zeit, 05.09.2000, Nr. 37). В данной ситуации имеет место игра слов по аналогии с Schutzengel - ангел-хранитель, метафоpa, с помощью оценочной функции выражается положительное отношение к тем, кто убирает мусор.

В слове Katzenjammerthal проявляются оценочная, экспрессивная и эстетическая функции: 
Bei einer kleinen Capelle wurde der Sarg niedergesetzt; da gab es nichts als Weinen und Schluchzen, und endlich trat eine alte Klatschrose hervor und hielt eine lange Leichenpredigt, worin sie viel schwatzte von den Tugenden der Hingeschiedenen, von einem irdischen Katzenjammerthal, von einem besseren Sein, von Liebe, Hoffnung und Glaube, Alles in einem näselnd singenden Tone, eine breitgewässerte Rede, und so lang und langweilig, daß ich davon erwachte. - У маленькой капелль стоял гроб, там все рыдали и плакали, и наконеи вылла одна сплетница и начала долгую проповедь над умершими, в которой она много болтала о добродетелях покойных, о земной эжизни, полной суеты, о лучшем бытии, любви, надежде и вере, все это гнусаво-напевным тоном, речь была такой пространной, длинной и нудной, что я в это время проснулся (Heine, Heinrich: Reisebilder. Bd. 3. Hamburg, 1830). В данном контексте присутствует слово с негативной коннотацией Katzenjammer-суета, катавасия, здесь подчеркивается, с одной стороны, тленность и суетность земной жизни и преимущество загробной, а с другой - ироническое и скептическое отношение автора к тому, что говорит женщина, ему кажется, что нет необходимости говорить об это так долго.

По результатам исследования на настоящий момент была выдвинута следующая гипотеза: блендинг в немецком языке широко распространен в масс-медиальном дискурсе и в художественной литературе, так как они стремятся к экспрессивности, оценочности, краткости, ставят цель привлечь внимание читателя или слушателя. Блендинг нехарактерен для научного стиля, тяготеющего к ясности, четкости, так как бленды менее семантически прозрачны, чем сложные слова, и идентификация их в большинстве случаев вызывает затруднения. В научном стиле всегда использовались в основном сложные слова и будут использоваться в дальнейшем. Возможно, что в будущем бленды будут использоваться в прессе и художественной литературе наравне со сложными словами. Данная гипотеза основана на природе блендинга, структуре и семантических особенностях немецкого языка и нуждается вдальнейшемдоказательствеииллюстрациинаконкретныхпримерах.

Также можно сделать вывод о том, что, хотя многие исследователи считают блендинг новым явлением в немецком языке, этот механизм начал использоваться достаточно давно (еще в XVIII веке, в частности, у Генриха Гейне).

\section{Библиография}

Лаврова Н. А. (2013), Контаминация как словотворческая модель: структура, семантика, прагматика (на материале современного английского языка), Москва.

Надькина О. А. (1991), Контаминация в свете теории речевой деятельности (на материале немеикого языка), Ленинград.

Friedrich C. (2008), Kontamination - Zur Form und Funktion eines Wortbildungtyps im Deutschen, Erlangen; Nurnberg. 


\title{
Tatyana Blinkova
}

\section{Functioning of Lexical Blending in Different Styles of German Language}

\begin{abstract}
Summary
The paper covers semantics and different functions of blends in German language. This issue is relevant, as blending is a very common and productive word-formation mechanism, though German blends have not been properly studied before the $90 \mathrm{~s}$. Blending in this context is handled as a wordformation mechanism and a phenomenon on the junction of linguistic competence and creativity. It is treated as both a linguistic and psychological phenomenon. The paper tackles functioning of blending in a variety of styles: mass-media, academic, colloquial speech, literature and other styles. Emphasis is made on semantics, stylistics and functions of blends. The paper involves reviews of works related to blends and evidence from my research. Blends are split into groups according to their subject-matter, stylistics, functions and origin.
\end{abstract}

